\title{
Statistical Analysis/Psychometric Modeling: Understanding and Influencing Societal Vulnerabilities to Terrorism
}

\author{
Dianne C. Barton and Patrick J. Barton*
}

\section{Introduction}

Qualitative analyses of historical, cultural, economic, religious, and sociological factors related to terrorism have produced powerful insights into the root causes and personal motivations of those involved. Efforts to understand and to counter ideological support for terrorism will require the insights gained from qualitative work, but could significantly benefit from the application of modern methods of statistical analysis and psychometric modeling. These models could extend the qualitative work of researchers such as Richardson, ${ }^{1}$ Atran, ${ }^{2}$ and Speckhard ${ }^{3}$ into the quantitative domain, where objective evaluation of alternative, actionable strategies is possible.

Mathematical models, often using Ajzen and Fishbein's Theory of Planned Behavior as a framework, can estimate relative strengths of association between measurable, experience-based attitudes, intention to engage in certain behaviors, and the manifest behaviors. ${ }^{4}$ The methods include structural, latent factor behavioral models used to quantify drivers of behavior. The behavioral models may be incorporated within dynamic simulation models to extend the scope and application of the findings into the temporal domain.

Private-sector companies have successfully applied these psychometric techniques to understand consumer psychological constructs for the purposes of finding the most highly leveraged means of inducing profit-related behavior. ${ }^{5}$ The underlying theories, methodologies, and tools can be applied across many cultures and to many types of businesses-ranging from business-to-consumer durable goods and telecommunications, to business-to-business financial services and raw materials.

We believe that these tools and techniques could also create a scientifically based understanding of the structure of individual decision processes (and the role of the individuals' social networks) related to participation in, or support of, terrorist activities. As is the case within the private sector, we believe that this understanding can be used

* Dianne C. Barton and Patrick J. Barton are Senior Fellows at the Institute for Science, Engineering, and Public Policy in Portland, Oregon.

1 Louise Richardson, What Terrorists Want: Understanding the Enemy, Containing the Threat (New York: Random House, 2006), 336.

2 Scott Atran, “Genesis of Suicide Terrorism,” Science 299 (March 2003): 1534-39.

3 Anne Speckhard and Khapta Akhmedova, "Talking to Terrorists," Journal of Psychohistory (Fall 2005): 125-56.

4 Icek Ajzen, “The Theory of Planned Behavior,” Organizational Behavior and Human Decision Processes 50 (1991): 179-211. (Note: Ajzen is also sometimes cited as Aizen.)

5 Patrick J. Barton and Bruce A. Corner, “Integrating Structural Modeling, Financial Linkages, and Initiative Development,” paper presented to the American Statistical Society (Joint Statistical Meetings), Alexandria, VA (2004). 
to support efforts to counter ideological support for terrorism, particularly to identify potential interventions, screen alternative initiatives, and estimate the effectiveness of proposed interventions with the population of interest.

This paper will first present a brief review of the Theory of Planned Behavior that frames the modeling approach, then will discuss the mathematical techniques used to support the scientific approach used in psychometric modeling as currently applied in the private sector. Finally, we will propose how psychometric modeling might be used as part of a research program dedicated to countering the ideological foundations of terrorism.

\section{Theory of Planned Behavior}

The Theory of Planned Behavior (TPB) and related work helps explain how people's attitudes can be influenced in order to change their behavior. ${ }^{6}$ This theory, well substantiated with quantitative research in several domains, holds that people's intentions to engage in behaviors are central to predicting actual behavior. TPB's predecessor, Ajzen and Fishbein's similar Theory of Reasoned Action, contends that intention and, therefore, action are determined primarily by attitude. The theory holds that the strength of intention is indicated by the person's subjective probability that he will perform the behavior in question. TPB resulted from the discovery that behavior is not completely voluntary and under control.

According to TPB, action is guided by three considerations:

1.Behavioral Beliefs: beliefs about the likely consequences of the behavior

2. Normative Beliefs: beliefs about the normative expectations of others

3. Control Beliefs: beliefs about the presence of factors that may facilitate or impede performance of the behavior.

First, an individual must believe that the behavior will produce a desired outcome. Second, the individual must believe that the behavior fits the normative expectations of others he cares about, such as his family or social circle. Finally, "control beliefs" are perceived beliefs about the ability of the individual to perform the behavior. Control beliefs might concern internal factors such as personal skills or abilities as well as external factors about the situation or the environment. People are not likely to form a strong intention if they believe they have no power or resources to carry out the behavior, even if they have positive attitudes toward the behavior.

6 See I. Ajzen, "Perceived Behavioral Control, Self-efficacy, Locus of Control, and the Theory of Planned Behavior,” Journal of Applied Social Psychology 32 (2002): 665-83; I. Ajzen and M. Fishbein, “The Influence of Attitudes on Behavior,” in The Handbook of Attitudes, D. Albarracín, B.T. Johnson, and M.P. Zanna, eds. (Mahwah, NJ: Lawrence Erlbaum Associates, 2005), 73-221; and M. Fishbein and I. Ajzen, Belief, Attitude, Intention, and Behavior: An Introduction to Theory and Research (Reading, MA: Addison-Wesley, 1975), 480. 


\section{Framework for Business Applications}

A deep vein of mathematically based research extends Fishbein and Ajzen's behavior intentions research into business applications. Using the behavioral intentions model as a theoretical framework, private-sector research firms have conducted numerous studies to identify strategies for affecting customer experiences for the purpose of influencing customer behavior. These studies can reveal non-intuitive insights about leverage points — or drivers of the behaviors of interest — and can guide resource allocation decisions around initiatives designed to enhance or suppress these behaviors.

Figure 1 represents the Theory of Planned Behavior as it is applied to business situations. Customer experiences shape attitudes, which activate emotions that strongly influence behavior. For business applications, these behaviors can generate financial results. Next, this general framework is specified in the form of a hypothesized structure of a behavioral model. The observed elements of the model, latent (unobserved) elements, and the causal relationships among the elements are drawn from a combination of general experience and qualitative research conducted with customers deemed to be representative of the study's target group. For business applications this qualitative research usually consists of in-depth, individual interviews or focus groups.

Figure 2 illustrates the general form of a typical behavioral model. Rectangles represent observed values. "Touchpoints" (sometimes called interaction areas) are points of contact between the company and its customers, and enter the model in the form of customers' overall impression of performance in each area. Depending on the company, touchpoints might include pre-sales support, product quality, warranty performance, reliability, etc. "Attributes" serve to specify customer evaluations of particular elements of the overall performance. Components of pre-sales support might include competent evaluation of the customer's needs, quality of the technical documentation, cogent answers to questions about the product, etc.

"Items," represented in Figure 2 in the column on the right, are observed indicators (scale items) of intangible, latent components of the model. While we cannot directly observe a customer's loyalty toward a company, we can recognize the behaviors and attitudes that demonstrate loyalty. These observations allow us to create a numerical scale for an immeasurable value, much as an individual's SAT test score, IQ, and high school grade point average could serve to "measure" the unobservable quality of "intelligence.” For loyalty, scale items typically include bottom-line oriented measures such as willingness to repurchase a product, likelihood that a customer will recommend it to a friend, inclination to buy more of it, etc. Ovals represent the latent components. For customer behavior models, these typically include motivations (both rational and

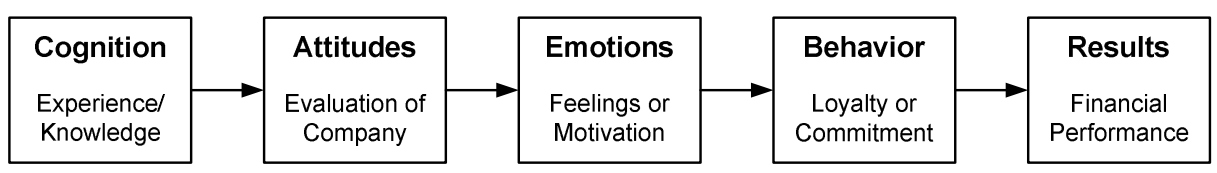

Figure 1: Framework Appropriate to Business Applications 


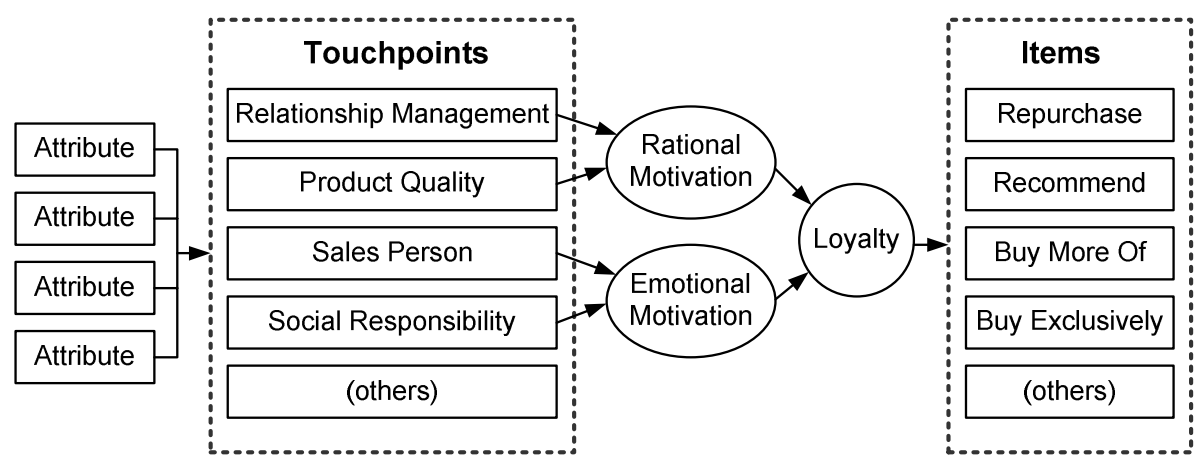

Figure 2: Hypothesized Behavioral Model

emotional), loyalty, identification with the brand or company, and expectations of the product. They represent the "Emotions" and "Behavior" components of the general structure presented in Figure 1.

The behavioral model shown in Figure 2 is a greatly simplified version compared to those usually used. Real-world models often employ more than 150 attributes, 10 touchpoints, 3-5 latent factors, and 20-30 scale items.

\section{Instrument Design and Measurement}

In the most successful studies, instruments designed to measure the model components are developed hierarchically, based on the hypothesized model structure. Measurements of overall experiences at the touchpoint level are deliberately coupled with measurements of the specific attributes, which in turn serve to refine separate aspects of each overall experience.

It is sometimes possible to estimate a model based on information gleaned from instruments or surveys not designed in this manner (for instance, from general attitudinal studies developed by the Pew Research Center, ${ }^{7}$ PIPA, ${ }^{8}$ etc.), but it is not likely that there will be a sufficient "fit" between this model and the information gathered in those surveys. The behavioral models rely on a combination of information about specific individual experiences, feelings about the experiences, and intentions seldom found in polls that focus on general opinions.

The sampling frame is designed to reflect the specific population whose behaviors are of interest. In the private sector, studies may focus on the general population of a marketplace, but much more often look at current customers, competitors' customers,

See, for example, Pew Research Center, “The Great Divide: How Westerners and Muslims View Each Other” (Washington, D.C.: Pew Global Attitudes Project Report, 22 June 2006).

8 See, for example, Program on International Policy Attitudes, "What the Iraqi Public Wants" (College Park, MD: PIPA, 2006). Available at: http://www.pipa.org/OnlineReports/Iraq/ Iraq_Jan06_rpt.pdf. 
recent defectors, potential defectors (those who experienced product quality problems, for example).

During the initial stages of developing a new model, studies usually include substantial oversampling to allow for the possibility that the target population as initially conceived really ought to be segmented because it represents two or more behaviorally distinct groups. As models become more "mature," the sampling can usually be pared back, but it still remains targeted at the populations that are the most behaviorally interesting.

General attitudinal surveys tend to focus on entire populations or, at best, subdivisions such as registered voters or women. ${ }^{9}$ While these are certainly insightful and interesting, the sampling frames are typically different from those applied in the development of behavioral intentions models.

We bring up the subjects of instrument design and sampling frame only to point out that the quantitative modeling that we are describing usually relies on a customized approach, and thus can't necessarily be grafted to existing research. Each of these topics is complex and richly developed in dozens of textbooks, so we will not pursue it further here. ${ }^{10}$

\section{Analyzing and Fitting the Model}

The data developed to support the model is analyzed using a combination of statistical techniques including structural equation modeling, linear regression, and factor score analysis. Structural equation modeling (SEM) ${ }^{11}$ lies at the heart of the analytical process, and is typically conducted with the aid of statistical packages such as Lisrel or AMOS. ${ }^{12}$ It is used to assess the validity of a theoretical model against observed data and to estimate the impact coefficients between each causally related pair of components.

The mathematics underlying SEM are not trivial, but the concepts are not difficult to understand. First, a theoretical model is developed (see discussion regarding Figure 2). One might think of our theoretical model as implying a set of causal relationships (A causes B, B causes C, etc.). The relationship between members of each pair (A/B, for instance) can be characterized by the degree to which the variability in one member corresponds to variability in the other member. This relationship is commonly quantified using a statistical measure called “covariance.” If we can quantify the variability

9 Ibid.

10 See Subir Ghosh, Multivariate Analysis, Design of Experiments, and Survey Sampling, in Statistics, a Series of Textbooks and Monographs, Vol. 159 (New York: Marcel Dekker, Inc., 1999), 698; and M.E. Thompson, Theory of Sample Surveys, Monographs on Statistics and Applied Probability, No. 74 (London: Chapman \& Hall, 1997), 305.

11 See Kenneth A. Bollen, Structural Equations with Latent Variables (New York: John Wiley \& Sons, 1989), 528.

12 Karl G. Jöreskog and Dag Sörbom, LISREL 8: User's Reference Guide (Lincolnwood, IL: Scientific Software International, 1996), 378. 
between members of every variable pair in our model, we can arrange them in a grid called a "covariance matrix" that provides a snapshot of the model structure. ${ }^{13}$

When we look at the observed data, we can easily apply the correct formula and calculate a covariance coefficient for each pair of variables. However, the theoretical model in Figure 2 postulates the existence of intangible latent variables, along with relationships between pairs of intangible variables. Clearly these relationships need to be estimated-and this is exactly what the SEM methodology accomplishes. More precisely, the statistical package utilizes the observed covariances (and assumptions about errors) and executes a simultaneous set of linear regressions to estimate a "best fit" solution for the entire model.

This estimated solution to our hypothesized model is then compared with the observed data using various measures of fit, parsimony, etc., to evaluate its acceptability. Technically speaking, we seek to reject the hypothesis that our model fits the data. If the fit is not acceptable, then the theoretical model or the assumptions must be reevaluated.

At the end of the process - assuming that we have accepted the model, of coursewe develop estimated impact coefficients for each relationship in our hypothesized model. We can then predict, with some degree of statistical certainty and theoretical justification, to what degree variables on the model's "left side"-that is, experiences-will influence variables on the "right side" - that is, behaviors. Alternatively, we can work backwards, beginning with behaviors, and explore the causal chain that leads to the root causes of these behaviors.

While SEM is the core methodology, in practice it is often supplemented with other techniques. Latent factor analysis is used to estimate scale validity, straight linear regression is used to link variables outside the main causal model to those within, and a variety of techniques are used to tie the behavioral outcomes to financial performance.

\section{Application of Insights}

Specific insights around behavioral intentions relating to customer behavior naturally vary from application to application, but some general phenomena may be observed. For instance, repeated studies of customer loyalty have found that emotional factors (such as trust) typically dominate rational factors (such as price or value) in predicting measurable behaviors like purchase decisions. Recent research in the durable appliance market found that emotional motivators have about twice the predictive power of rational ones. Even in relatively "hard-nosed" business-to-business sectors, such as distribution channels, where one might think that only money matters, rational and emotional factors have roughly the same predictive power. Figure 3 illustrates industry-ag-

${ }^{13}$ George W. Snedecor and William G. Cochran, Statistical Methods, $8^{\text {th }}$ ed. (Ames, IA: Iowa State Press, 1989), 503. 
gregated standardized impact coefficients between rational motivation/ loyalty and emotional motivation/loyalty. ${ }^{14}$
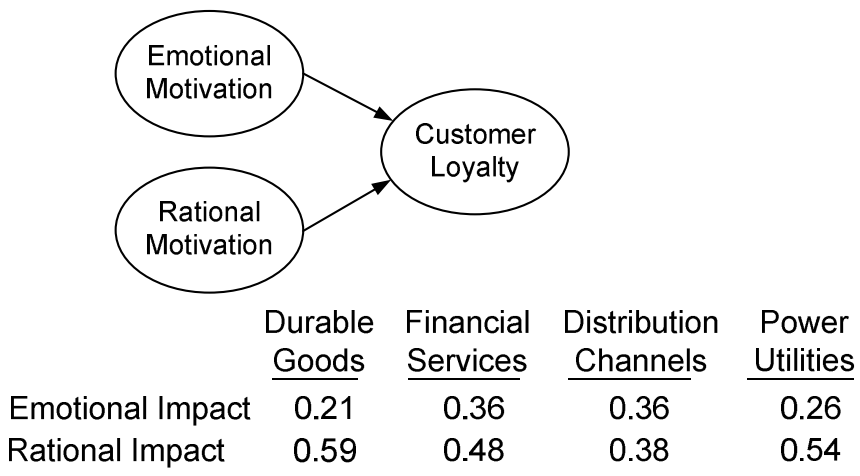

Figure 3: Emotional versus Rational Impacts on Loyalty

These general relationships between emotional and rational motivations have proven robust over time and, when data is available, across different cultures.

For any particular study, the resulting model and parameters can be examined to identify areas in which specific initiatives might be developed to maximize the impact on the relevant behaviors. In our example, we can compare the standardized impact coefficients (ßs) of the touchpoints to determine which are relatively most important by tracing each path for an individual touchpoint to loyalty. For instance, the impact of Product Quality on loyalty is simply:

Product Quality to Loyalty $ß=$

Product Quality to Rational Motivation $\beta$ * Rational Motivation to Loyalty ß +

Product Quality to Emotional Motivation $ß$ * Emotional Motivation to Loyalty $ß$

If the model solution yielded an impact of 0.20 for Product Quality and 0.40 for Relationship Management, we could say that Product Quality is twice as important, and that the same amount of change (in standardized units) in Product Quality would have twice as much of an impact on customer loyalty. This would enable us to make informed decisions about where to allocate resources in order to have the maximum impact on our target audience.

These path calculations are typically extended to evaluate the effect through the entire model of attributes (representing the experiences) to the items (representing the behaviors). This process allows us to determine which experience(s) we need to change in order to have the largest impact on the behaviors we care about.

${ }^{14}$ L.A. Crosby and S.L. Johnson, "Understanding Customer Needs and Expectations: The First Step to Delivering a Positive Experience,” paper presented to Customer Experience Management Conference, The Conference Board (2005). 
The model also yields an unstandardized solution that provides the same type of impact coefficients, but is scaled to the natural units of the experiences/behaviors we have measured. For example, using these coefficients, we can quantify the effect of moving the mean of a population's experience ("Attribute A," for example) from 2.5 to 3.5 on the mean of a behavioral item ("Repurchase," for example). In a typical commercial application, external economic analysis would provide information about the relationship between repurchase behavior and profitability. When the model parameters and economic analysis are combined, it becomes possible to calculate figures of merit such as net present value or return on investment for initiatives designed to address different experiences.

\section{Dynamic Simulation}

The calculations involved in applying modeling insights to strategy development are tedious and, for most, highly uninteresting. Moreover, they yield only a static "snapshot" of the result of any initiative. To address these and other issues, the model and its parameters can be encapsulated into accessible dynamic simulation environments, sometimes with interactive, video game-style interfaces.

Dynamic models are structured to capture and reproduce the changing behavior of systems over time, and can incorporate critical operating assumptions that reflect "real world" implementation issues. Operating assumptions may include how much we expect an initiative to cost, how long it would take to launch, how long it would take to reach the intended audience, and the maximum fraction of the intended audience we could ever reach. Other assumptions might involve how our initiative would affect a "bundle" of experiences, perhaps in different touchpoint areas. For instance, if we make a product more energy efficient, our customers might perceive it as providing better value because it is less expensive to use. They might also perceive us as more socially responsible for using fewer natural resources.

Dynamic simulation models are also capable of representing the effects of both internal feedback and external forces acting on the system. As such, they can capture complex interactions, feedback loops, nonlinearities, delays, and transient responses, and can provide a framework that integrates behavioral modeling information with the environment in which it is applied. Typically, these dynamic models are utilized to structure idea building sessions, to screen large numbers of competing initiatives, to interface with management tools, and to communicate the findings of the behavioral models to non-technical audiences.

\section{Potential Uses in Countering Ideological Support for Terrorism}

In regions currently experiencing conflict, it is likely that religious passions, emotional reactions to military presence, and stress caused by daily violence are salient features of the population's psychological landscape. It is also likely that decisions to engage in many activities-e.g., demonstrations, insurgency, participation in the government, participation in the workforce-are psychologically as well as rationally motivated. If this is the case, applying behavior intentions theory and modeling could enrich the discussion of how to put information gleaned from data mining activities into context. 
We suggest that psychometric modeling in conjunction with dynamic simulation could support efforts to counter ideological support for terrorism by offering:

- A method to better identify the root causes of terrorism and the relative impacts of these root causes

- A decision support tool that would estimate the effect of various interventions taken to influence the behavior of at-risk populations-i.e., intervention through media, religious leaders, peers, family, social groups, etc.

- A methodology to more rigorously collect and analyze survey data that is needed to measure the effectiveness of government interactions

- Information to support other computer simulation approaches such as network formation modeling, agent-based simulation, complex social system models, etc.

- A more robust method to measure the impact of investments in "soft power" interventions.

The results of such psychometric analysis would also be highly compatible with social analysis techniques like agent-based modeling and network analysis, and could be applied to understand both current/potential actors and participants in the social networks upon which they depend. Psychometric modeling could provide a method to quantitatively instantiate agents in complex social system models.

\section{Conclusion}

Tools and methodologies successfully employed by private-sector companies in pursuit of profit could also be employed to understand and combat insurgent and terrorist movements. These tools could provide the framework to develop theoretically based and quantitatively supported initiatives aimed at changing the experiences, and thus the behaviors, of those who engage in or support terrorist activities. 
THE QUARTERLY JOURNAL

\section{Bibliography}

Ajzen, I.. "Perceived Behavioral Control, Selfefficacy, Locus of Control, and the Theory of Planned Behavior." Journal of Applied Social Psychology 32 (2002).

Ajzen, Icek. "The Theory of Planned Behavior." Organizational Behavior and Human Decision Processes 50 (1991): 179-211.

Atran, Scott. "Genesis of Suicide Terrorism." Science 229 (2003).

Richardson, Louise. What Terrorists Want: Understanding the Enemy, Containing the Threat. New York: Random House, 2006.

Snedecor, George W., and William G. Cochran. Statistical Methods. Ames, IA: Iowa State Press, 1989.

Speckhard, Anne, and Khapta Akhmedova. "Talking to Terrorists." Journal of Psychohistory (2005): 125-56. 